\title{
Article \\ Numerical and Experimental Investigations of Micro Thermal Performance in a Tube with Delta Winglet Pairs
}

\author{
Jiangbo Wang ${ }^{1,2}$, Ting Fu ${ }^{1,2, *}$, Liangcai Zeng ${ }^{1,2}$, Guang Chen ${ }^{3,4}$ and Fue-sang Lien 4 \\ 1 Key Laboratory of Metallurgical Equipment and Control Technology, Wuhan University of Science and \\ Technology, Wuhan 430081, China; qdgwbs@163.com (J.W.); zengliangcai@wust.edu.cn (L.Z.) \\ 2 Ministry of Education \& Hubei Key Laboratory of Mechanical Transmission and Manufacturing Engineering, \\ Wuhan University of Science and Technology, Wuhan 430081, China \\ 3 Key Laboratory of Traffic Safety on Track, Central South University, Ministry of Education, \\ Changsha 410000, China; gszxcgsp@163.com \\ 4 Department of Mechanical \& Mechatronics Engineering, University of Waterloo, \\ Waterloo, ON N2L 3G1, Canada; fslien@uwaterloo.cn \\ * Correspondence: futing123gh@wust.edu.cn
}

check for updates

Citation: Wang, J.; Fu, T.; Zeng, L.; Chen, G.; Lien, F.-s. Numerical and Experimental Investigations of Micro Thermal Performance in a Tube with Delta Winglet Pairs. Micromachines 2021, 12, 786. https://doi.org/ $10.3390 / \mathrm{mi1} 2070786$

Academic Editor: Kwang-Yong Kim

Received: 11 June 2021

Accepted: 28 June 2021

Published: 30 June 2021

Publisher's Note: MDPI stays neutral with regard to jurisdictional claims in published maps and institutional affiliations.

Copyright: (c) 2021 by the authors. Licensee MDPI, Basel, Switzerland. This article is an open access article distributed under the terms and conditions of the Creative Commons Attribution (CC BY) license (https:// creativecommons.org/licenses/by/ $4.0 /)$.

\begin{abstract}
In this research, a novel vortex generator (VG) is presented. The experimental and numerical investigations were carried out to study the micro thermal-hydraulic performance in a heated tube. The numerical results showed that the fluid in the core flow region and the near-wall region was fully mixed because of the longitudinal vortices created by the vortex generators. In addition, the experimental results showed that the heat transfer coefficient $(h)$ decreased with the increasing pitch ratio $(P R)$ value, while the friction coefficient exhibited the opposite trend. With the increasing ration angle $(R A)$ numbers, the $h$ values decreased while the $f$ numbers increased. In addition, the maximum and minimum values of the fraction ratio were 1.66 and 4.27 , while these values of the Nusselt number ratio were 1.24 and 1.83. The maximum thermal enhancement factor (TEF) was 1.21 when $P R=0.5, R A=0^{\circ}$ and $R e=9090$. The heat transfer enhancement mechanism of the vortex generator is explained from the microscopic point of view.
\end{abstract}

Keywords: new vortex generators; heat transfer enhancement; multi-longitudinal vortices

\section{Introduction}

With the increase in serious energy problems in recent years, higher requirements for energy utilization and recovery have been put forward. The convective heat transfer method was widely used to improve energy efficiency by enhancing heat transfer efficiency in the process of energy consumption.

Heat transfer enhancement technology of single-phase flow was generally divided into three categories [1] and the passive method was more common in practical applications for low cost, easy maintenance and no reliance on external energy contrast of the active method and compound method [2,3]. Vortex generators (VGs) which were placed in tubes of heat exchangers, were regarded as an important passive method to enrich energy efficiency. The role of the VGs was to create multi-longitudinal vortices (MLVs), which could result in better mixing of the fluid and restrain the growth of the thermal boundary layer. Thus, the MLVs played a decisive role in enhancing heat exchange efficiency [4].

In fact, wings [5] and winglets [6] were widely used due to many advantages, including simple to manufacture, low cost, and low-pressure drop [7-9]. Ke et al. [10] numerically investigated the heat transfer performance (HTP) of different winglet arrangements in a rectangular channel. They believed that the channel height and the aspect ratio of VGs were the two major parts affecting the TEF. They also used the "Method of Images" to analyze the dynamic characteristics of the MLVs in the channel. Sun et al. [11] studied the influence of three arguments of RWVGs on the HTP in a heated tube. They reported 
that the height of RWVG s had a great impact on the induced MLVs, and the HTP was enriched significantly with a lower pitch ratio of the RWVG's. The influence of different delta winglet arrangements on HTP was studied by Khoshvaght-Aliabadi et al. [12]. Their experimental results showed that the heat transfer coefficient $(h)$ and friction factor $(f)$ increased with the application of VGs. The best TEF was 1.41 when the Reynold number $(R e)$ was 8715.

Xu et al. [13] discussed the internal flow behaviors and different distributions of $N u, f$ and TKE caused by VGs with different attack angles and blocking ratios numerically. The effects of different structures of VGs on the improvement of overall thermal performance were explained based on the estimation of the axial turbulent wake. Liang et al. [14] found that the WVG installed in the tube could produce MLVs and provided a higher level of turbulence with relatively low-pressure loss. Subsequently, Xu [15] and Zhai [16] conducted experimental studies on the thermal behavior of winglets. To better explore the basic mechanism of heat transfer, they demonstrated MLVs through a high-speed camera and a smoke generator. Pourhedayat et al. [17] carried out a numerical study on the new positioning of the DWVGs applied in a tube. The HTP of DWVGs with backward and forward configurations were analyzed. Hatami et al. [18] proposed a new heat exchanger for diesel engines. $20 \mathrm{VGs}$ were applied with the best size and angle of attack in the exhaust. The $N u, f$ and exergy recovery of the simple two-tube heat exchanger were compared with those of the simple two-tube heat exchanger. Oneissi et al. [19] numerical studied the thermal behavior of IPWPVGs. They pointed that the IPWP has lower pressure loss because of its special design.

To improve the HTP of the VGs, some new VGs were proposed and studied. He et al. [20] numerically simulated the HTP of plate-fin tube-shell heat exchangers. On the basis of the field synergy principle (FSP), they thought that reducing the crossing angle between two fields including the velocity field and temperature gradient field was the underlying mechanism of strengthening convective heat exchange. They also suggested that slotting and other techniques should be used at the rear of the fin to improve the coordination of the two fields. Baissi et al. [21] investigated the HTP and energy loss of a SAH channel fitted with VGs experimentally. After analyzing the flow structure of perforated and non-perforated curved delta-shaped VGs, they found that the perforated VGs suffered relative lower pressure loss penalty, but the non-perforated delta-shaped VGs had a maximum TEF of 2.21. Lu et al. [22] studied the flow characteristics of punched planar VGs and curved VGs, respectively. They believed that punching holes on the surface of VGs could achieve better HTP, and the better hydraulic performance was achieved at a lower position and near the leading edge of the punched holes. Skullong et al. [23] carried out an experimental study on the convective heat transfer in a heated tube by placing several pairs of perforated delta winglets repeatedly on the perforated-cross tape. They found that the $f$ values were decreased with the punched holes.

Song et al. [24] studied the HTP of the concave and convex curved VG under the condition of laminar flow in a rectangular channel at different central angles $\left(10^{\circ}-80^{\circ}\right)$ and three different attack angles $\left(20^{\circ}, 30^{\circ}, 40^{\circ}\right)$. The numerical result showed that the HTP of the concave curved VG was best when the central angle was greater than $60^{\circ}$ and the angle of attack was $20^{\circ}$, while the HTP of convex curved VG was inhibited. Agung [25] experimentally studied the HTP of the tube with the insertion of punched delta-winglets (PDWVGs) at $5500<R e<14,500$. Three different attack angles $\left(\alpha=30^{\circ}, 50^{\circ}, 70^{\circ}\right)$, pitch ratio (1.05), and width ratio (0.42) of the PDWVGs were investigated, respectively. The results showed that the $f$ values increased as $\alpha$ increased. The maximum TEF was found to be 1.22 when $\alpha$ was $70^{\circ}$. Another punched VGs with holes was studied by Gupta [26], they pointed that punched winglets with different positions had different effects on the overall HTP.

Thus, from the above literature we could find that the MLVs induced by the VGs could improve the HTP significantly. Under the excitation of the insert of WVG, a new type of VG was proposed, which was composed of two delta winglets and a backward inclination angle 
(namely, DWPVG), and the structure of MLVs created by the DWPVGs and their effect on the HTP was studied. Besides, the influence of three pitch ratios $(P R=l / D=0.5,1.0,1.5)$ and the four rotation angles $\left(R A=\beta=0^{\circ}, 3.3^{\circ}, 6.7^{\circ}, 10^{\circ}\right)$ of the DWPVGs on the HTP were investigated. The results were explained based on the convective transport equation of heat flux from the micro point of view, respectively. The TEF of this work was then compared with the work of predecessors.

\section{Model Description}

\subsection{Details of the DWPVGs}

The detail of the designed DWPVGs was depicted in Figure 1. ABS material was selected to form the DWPVGs by 3D print method, which was shown in Figure 1a. Each DWPVG was composed of two identical triangular winglets with a backward inclination angle. The dimensions of a single DWPVG were shown in Figure 1b. These DWPVGs were mounted on rings ( $5 \mathrm{~mm}$ width and $1.5 \mathrm{~mm}$ height) with two thin rods ( $2 \mathrm{~mm}$ diameter) were applied to connect these rings. Figure 1c shows the diagram of the test section with DWPVGs which were connected with rings and rods with glue (HY-106AB). The schematic diagram of DWPVGs placed in the tube is shown in Figure 1d. The DWPVGs were $150 \mathrm{~mm}$ away from the entrance of the test section. Every six DWPVGs were uniformly arranged in the circumferential direction of the tube. Two planes were located at $\mathrm{x} 1=1735 \mathrm{~mm}$ and $\mathrm{x} 2=1740 \mathrm{~mm}$ for further discussion. Along the $\mathrm{x}$-direction, the rotation angle of the down circumferential arranged DWPVGs relative to the up DWPVGs was defined as $\beta$. The heat transfer characteristics were discussed with three pitch ratios $(P R=l / D=0.5,1.0,1.5)$ and four rotation angles $\left(R A=\beta=0^{\circ}, 3.3^{\circ}, 6.7^{\circ}, 10^{\circ}\right)$, respectively.

(a)

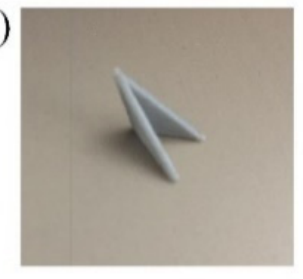

(c)

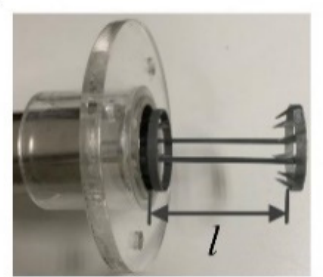

(b)

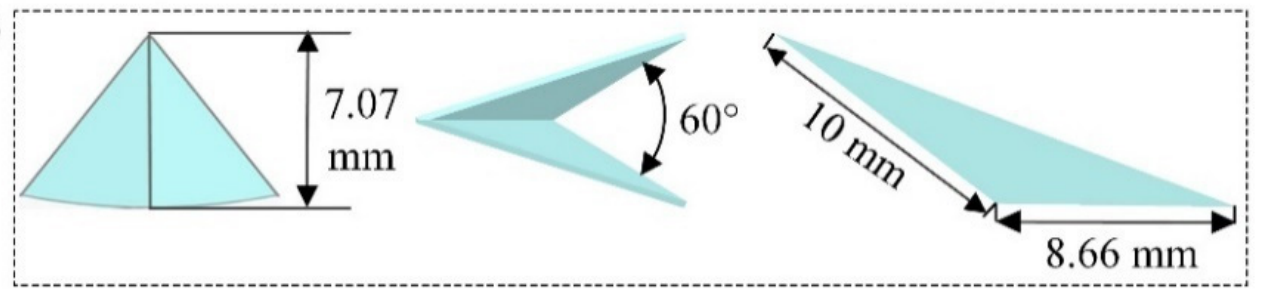

(d)

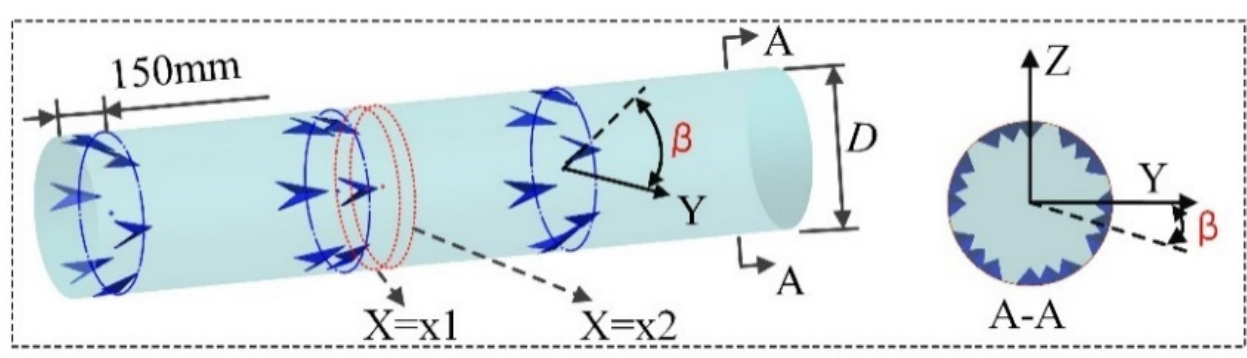

Figure 1. The DWPVG and test section. (a) Real photograph of a single DWPVG, (b) schematic of DWPVG, (c) real photograph of the test section with DWPVGs, (d) schematic of the test section.

\subsection{Experimental Setup}

The experiments were performed in this section and the schematic of the experimental facility was presented in Figure 2. The experimental facility compromised an air blower and three sections (namely upstream section, test section, and downstream section). The tube was made of 304 stainless steel with an inner diameter of $51 \mathrm{~mm}$ and $1.5 \mathrm{~mm}$ thickness. The lengths of the three sections were $1500 \mathrm{~mm}, 500 \mathrm{~mm}$ and $200 \mathrm{~mm}$, respectively. The length of the upstream section was set to $1500 \mathrm{~mm}$ to reduce the uneven flow in the experiment. The fluid was in a fully developed state when it entered the test section. The parts were connected by a PC flange. The speed of the blower was adjusted through the voltage stabilizer and the voltage regulating transformer. The air flow into the tube was controlled through the valve, and the wind speed at the exit of the tube was measure 
using an electronic anemometer (hf8120). Two $3 \mathrm{~mm}$ micro holes were turned both in the inlet and outlet of the test section and connected with the pressure gauge through the hose. The pressure drop between the two sides was measured through the pressure converter. The flexible hose was winded at the outside of the tube. Hot water was circulated through pumps and hoses and insulation was used to keep the pipe at a constant high temperature condition of the tube. Eight T-type thermocouples were uniformly attached to the inner wall of the tube through a small hole with a diameter of $2 \mathrm{~mm}$. Two T-type thermocouples were placed at the entrance and outlet of the test section to measure the temperature, respectively. Foam copper was also used at the exit of the test section to improve the measurement accuracy. The experimental device was placed in a closed room. The environment temperature was adjusted through air conditioning to make sure the temperature at the entrance of the tube was uniform and equal to the room temperature. All temperature data were connected to a multi-channel data recorder and displayed on the PC.

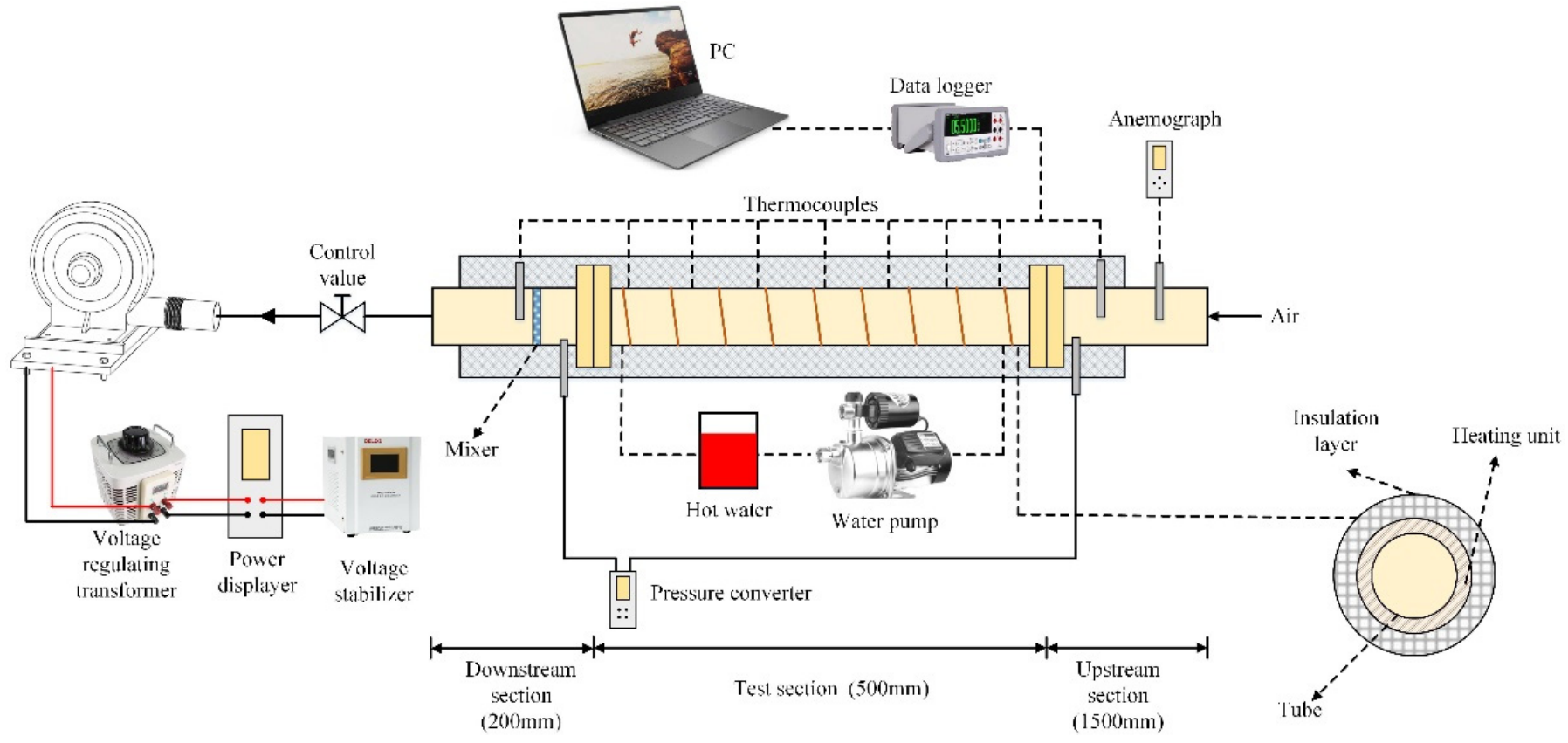

Figure 2. Schematic of the experiment facility.

\subsection{Data Reduction and Uncertainty Analysis}

The heat transfer rate in the air-side was determined as follows [27]:

$$
Q=\widetilde{m} \times C_{p} \times\left(T_{m, o u t}-T_{m, \text { in }}\right),
$$

where, $\widetilde{m}$ and $C_{p}$ represented the mass flow rate and specific heat of the air at the bulk temperature, respectively. $T_{m, o u t}$ and $T_{m, \text { in }}$ were the average temperature of the crosssection located at the inlet and outlet of the test section, and calculated as follows:

$$
\begin{aligned}
T_{m, \text { out }} & =\left(T_{m, \text { out }, 1}+T_{m, \text { out }, 2}\right) / 2 ; \\
T_{m, \text { in }} & =\left(T_{m, \text { in }, 1}+T_{m, \text { in }, 2}\right) / 2 .
\end{aligned}
$$

The heat transfer coefficient was determined by:

$$
h_{t}=Q / A\left(T_{\text {inner,wall }}-T_{b}\right) .
$$


In Equation (4), $A$ and $T_{\text {inner,wall }}$ are the area and mean temperature of the inner surface of the test section, $T_{b}$ is the bulk temperature of the test section and the $T_{\text {inner,wall }}$ and $T_{b}$ are given by:

$$
\begin{gathered}
T_{\text {inner,wall }}=\sum T_{\text {inner }, \text { wall }} / 8 ; \\
T_{b}=\left(T_{\text {in }}+T_{\text {out }}\right) / 2 .
\end{gathered}
$$

The $R e$ and $f$ are defined as:

$$
\begin{gathered}
\operatorname{Re}=\rho u_{i n} d_{c} / \mu ; \\
f=2 \times \Delta p \times d_{c} /\left(L \rho u_{i n}{ }^{2}\right) .
\end{gathered}
$$

In the above equations, $\rho$ and $\mu$ are the density and thermal conductivity of air based on $T_{b} . u_{i n}$ is the mean velocity measured at the entrance of the upstream section. $d_{c}$ and $L$ denote the hydraulic diameter of the tube and the length of the section, respectively. $\Delta p$ represents the pressure drop between the inlet and outlet of the test section.

The $N u$ is determined by:

$$
N u=h \times \frac{d_{c}}{\lambda}
$$

where $\lambda$ is the thermal conductivity of the air based on the $T_{b}$.

The TEF $[28,29]$ is given by:

$$
T E F=\left(\frac{N u}{N u_{0}}\right)\left(\frac{f}{f_{0}}\right)^{-\frac{1}{3}}
$$

where $N u_{0}$ and $f_{0}$ are the Nusselt and friction of tube absence of DWPVGs, respectively.

The method recommended by the literature $[30,31]$ was used to analyze the uncertainties of the present experiment. The maximum uncertainties of three parameters including $R e, f$ and $N u$ were $0.2 \%, 2.95 \%$ and $7.07 \%$, respectively.

\section{Numerical Simulation}

\subsection{Simulation Method}

The fluid flow and the HTP of the heated tube with a plurality of DWPVGs were conducted to clearly understand the mechanism of the heat transfer enhancement. To simplify the simulation, we made the following assumptions:

1. The medium (air) was Newtonian and had constant properties.

2. Viscous dissipation and gravity were ignored.

3. The insert was considered rigid.

In the turbulence simulation, the appropriate turbulence model played a decisive role in the simulation results. The widely used models including Realizable $k-\varepsilon$, Standard $k-\varepsilon$, Standard $k-\omega$ and SST $k-\omega$ are compared in Figure 3. The simulation results of SST $k-\omega$ model proposed by [32] are in good agreement with the experimental results with a maximum error of $3.99 \%$. Thus, the SST $k-\omega$ model was selected for further investigation. The governing equations are available in the literature [33].

All governing equations were solved by commercial CFD software STAR CCM+, which is based on the finite volume method. The SIMPLE algorithm was selected to deal with the pressure velocity coupling problem. The energy, momentum and turbulence equations were discretized by the second-order upwind scheme, and the solutions were considered convergent when the residuals of the continuity equation, momentum equation and turbulence equation were less than $10^{-5}$ and the energy equation was less than $10^{-7}$. 


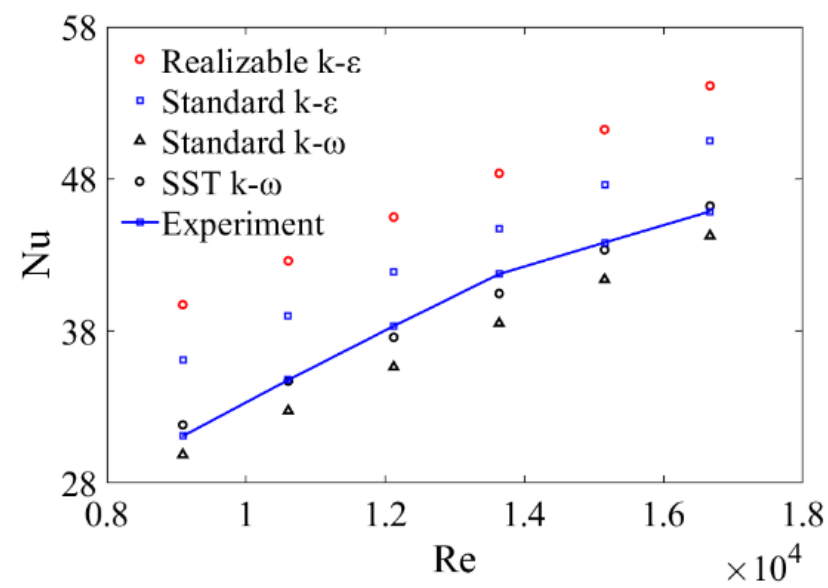

Figure 3. Comparison of different models of $P R=1.5, R A=30^{\circ}$.

\subsection{Boundary Conditions and Numerical Method}

In the numerical simulation, the Re number ranged from 9090 to 16,660 . The DWPVGs were set to be insulated and the boundary conditions adopted in the three sections are listed in Table 1.

Table 1. Boundary conditions of the simulation.

\begin{tabular}{cr}
\hline Region(s) & Conditions \\
\hline Fluid inlet & $u(x, y, z)=u_{\text {in }}=$ const, $v(x, y, z)=w(x, y, z)=0, T(x, y, z)=T_{\text {in }}=293 \mathrm{~K}$ \\
Fluid outlet & $\frac{\partial u(x, y, z)}{\partial x}=\frac{\partial v(x, y, z)}{\partial x}=\frac{\partial w(x, y, z)}{\partial x}=\frac{\partial T(x, y, z)}{\partial x}=0, T_{\text {out }}=293 \mathrm{~K}$ \\
Wall surfaces & $u(x, y, z)=0, v(x, y, z)=0, w(x, y, z)=0, T(x, y, z)=T_{w}=343 \mathrm{~K}$ \\
DWPVGs surfaces & $u(x, y, z)=0, v(x, y, z)=0, w(x, y, z)=0$ \\
\hline
\end{tabular}

STAR CCM+ commercial software was used to generate the unstructured grid (see Figure 4). To obtain accurate results within the boundary layer of all surfaces, grid refinement was implemented, and the largest value of $y+$ was less than 1.
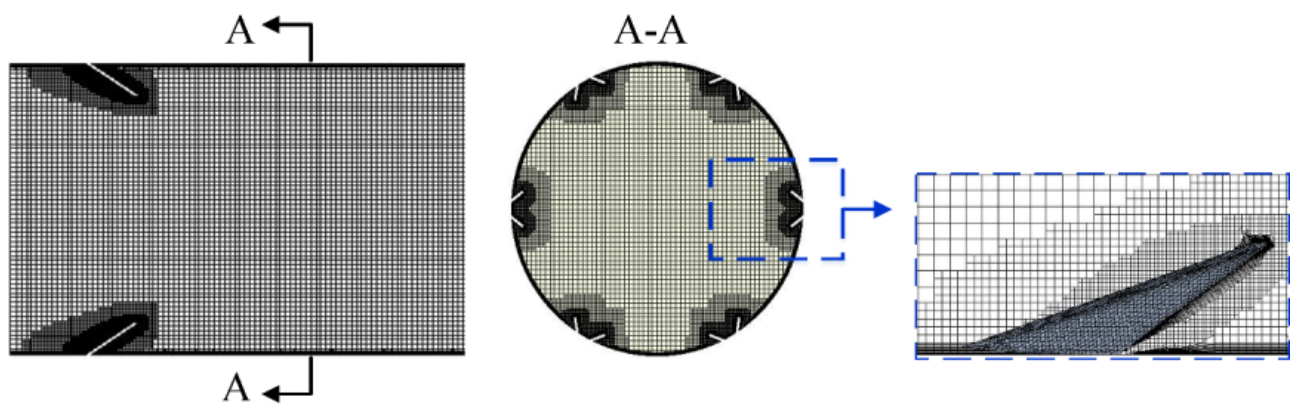

Figure 4. The grids generated of $P R=1.5, R A=30^{\circ}$.

As illustrated in Figure 5, four different grid sizes were checked off: $P R=1.5$, $R A=10^{\circ}$ with 3 million, 7 million, 11 million and 19 million at $R e=9090$, respectively. The number of grids increased from $11,220,383$ to $19,119,226$ and the maximum deviations of $N u$ and $f$ were $0.012 \%$ and $0.16 \%$, respectively. Therefore, the grid system with $11,220,383$ was selected for subsequent simulations. 


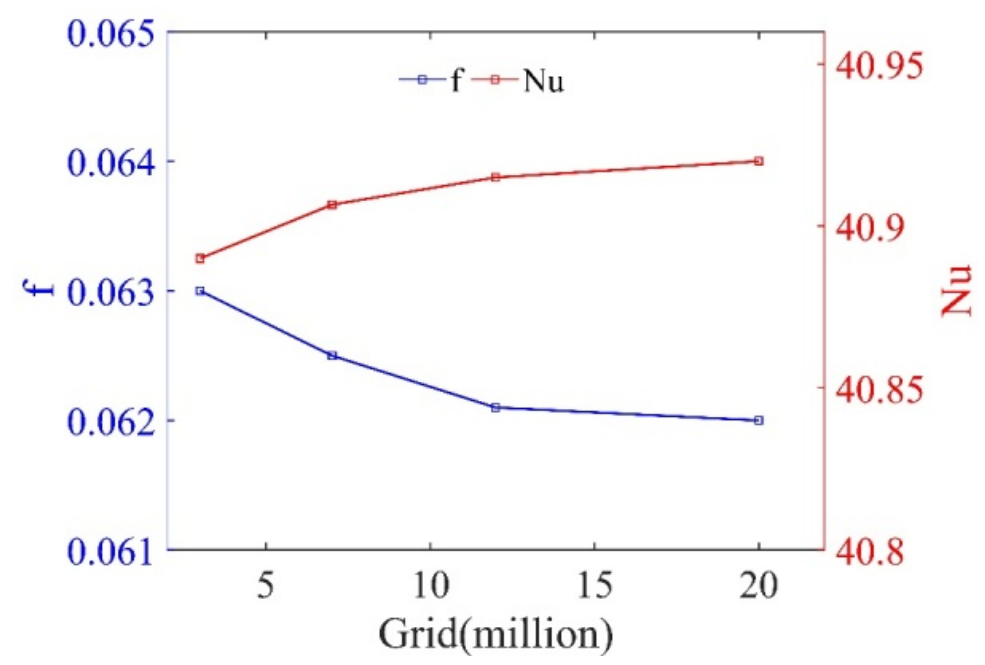

Figure 5. Grid independence test of $P R=1.5, R A=30^{\circ}$.

\subsection{Verification of the Smooth Tube}

$N u$ and $f$ of the experimental results of the smooth tube were served to verify the precision of the results with the following well-established empirical correlations:

$$
N u=\frac{(f / 8)(R e-1000) \operatorname{Pr}}{1+12.7(f / 8)^{1 / 2}\left(\operatorname{Pr}^{2 / 3}-1\right)} \times\left(1+\left(\frac{D}{L}\right)^{2 / 3}\right)
$$

Gnielinski correlation [34];

$$
N u=N u_{m, T}(R e=2300)+\frac{(f / 8)(R e-2300) P r^{1.008}}{1.08+12.39(f / 8)^{1 / 2}\left(P r^{2 / 3}-1\right)} \times\left(1+\left(\frac{D}{L}\right)^{2 / 3}\right)
$$

Taler correlation [35];

$$
f=(0.79 \ln R e-1.64)^{-2}
$$

Petukhov correlation [36];

$$
f=0.316 R e^{-0.25}
$$

Blasius correlation [37];

$$
f=(1.2776 \log R e-0.406)^{-0.25}
$$

Taler correlation [38].

As illustrated in Figure 6, the $N u$ and $f$ of the experimental system established were in accordance well with the empirical correlations. Compared to Gnielinski and Talor correlations, the maximum deviation of $N u$ were $16.2 \%$ and $17.8 \%$, while the maximum error of $f$ related to Petukhov, Blasius and Taler correlations were $7.71 \%, 7.89 \%$ and $8.06 \%$, respectively, which could mean the model established in this paper was valid. 


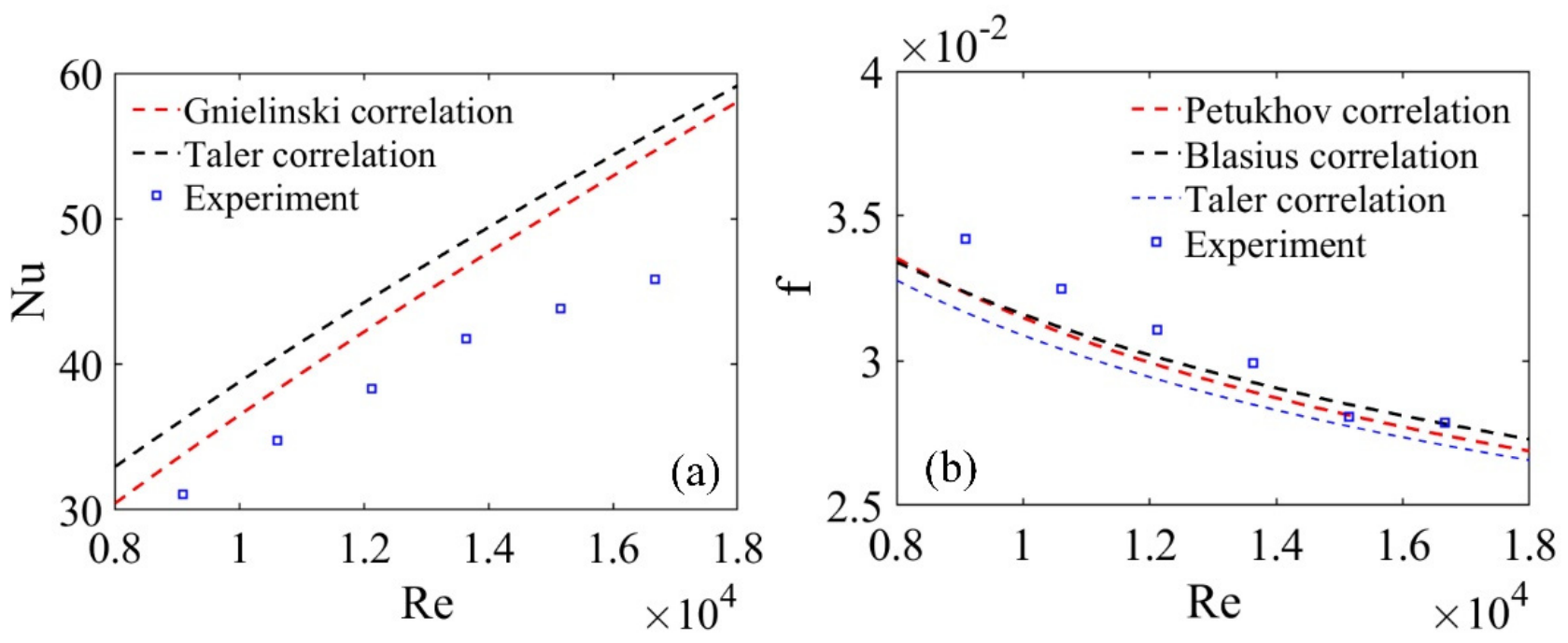

Figure 6. Verification of the smooth tube: (a) nusselt number, (b) friction factor.

\section{Results and Discussion}

\subsection{Effects of VG's Arrangement Styles on Heat Transfer Coefficient}

Figure 7a shows the relationship of $R e$ and $h$ for these tubes with different $P R s, R A s$ and Res. The experimental results indicate that the values of $h$ were higher for the tubes with VGs compared to smooth tubes due to the existence of MLVs from VGs. Figure 7b shows the relationship of $R A$ and $h$ when the values of $P R$ and $R e$ are the same. The curves explained that the values of $h$ decreased with an increase in the values of $R A$. This means the heat transfer performance was restrained when the values of $R A$ increased. Figure 7c shows the relationship of $P R$ and $h$ when the values of $R A$ and $R e$ are the same, highlighting that the HTP was poor when the $P R$ values increased.

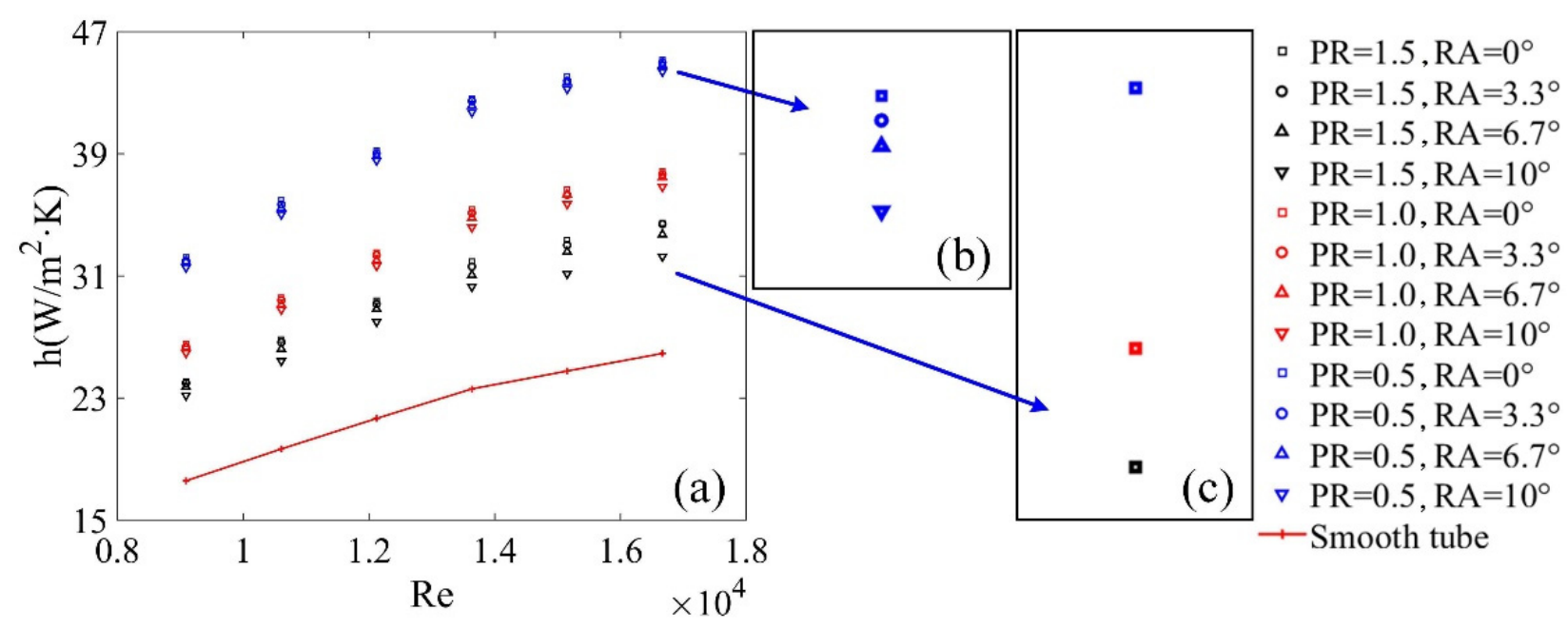

Figure 7. Effects of vortex generators on the $h$ for different $P R$ s and $R A s$. (a) the relationship of $R e$ and $h$ for these tubes with different $P R \mathrm{~s}, R A \mathrm{~s}$ and Res; (b) the relationship of $R A$ and $\mathrm{h}$ when the values of $P R$ and $R e$ are the same; (c) the relationship of $P R$ and $\mathrm{h}$ when the values of $R A$ and $R e$ are the same.

The $h$ was determined by heat flux $q$, and heat flux $q$ was determined by velocity, velocity gradient and the combination of velocity and velocity gradient in liquid convective transport. More information can be found in [39].

The convective transport equation of heat flux for steady state flow was as follows:

$$
(v \cdot \Delta) q+e_{i j} \cdot q=\alpha \nabla^{2} q
$$


where $q=-\lambda \nabla T$ and $e_{i j}=\nabla v, \lambda$ represented thermal conductivity.

In the three directions $(x, y, z)$, the Equation (16) could be written as:

$$
\begin{aligned}
& \left(u \frac{\partial q_{x}}{\partial x}+v \frac{\partial q_{x}}{\partial y}+w \frac{\partial q_{x}}{\partial z}\right)+\left(q_{x} \frac{\partial u}{\partial x}+q_{y} \frac{\partial v}{\partial x}+q_{z} \frac{\partial w}{\partial x}\right)=\alpha \nabla^{2} q_{x} \\
& \left(u \frac{\partial q_{y}}{\partial x}+v \frac{\partial q_{y}}{\partial y}+w \frac{\partial q_{y}}{\partial z}\right)+\left(q_{x} \frac{\partial u}{\partial y}+q_{y} \frac{\partial v}{\partial y}+q_{z} \frac{\partial w}{\partial y}\right)=\alpha \nabla^{2} q_{y} \\
& \left(u \frac{\partial q_{z}}{\partial x}+v \frac{\partial q_{z}}{\partial y}+w \frac{\partial q_{z}}{\partial z}\right)+\left(q_{x} \frac{\partial u}{\partial z}+q_{y} \frac{\partial v}{\partial z}+q_{z} \frac{\partial w}{\partial z}\right)=\alpha \nabla^{2} q_{z} .
\end{aligned}
$$

Equations (17)-(19) could be rewritten further as follows:

$$
\begin{aligned}
& w_{c-x}+w_{e-x}=\alpha \nabla^{2} q_{x} ; \\
& w_{c-y}+w_{e-y}=\alpha \nabla^{2} q_{y} ; \\
& w_{c-z}+w_{e-z}=\alpha \nabla^{2} q_{z} ;
\end{aligned}
$$

where $w_{c x}, w_{e x}, w_{c y}, w_{e y}, w_{c z}$ and $w_{e z}$ are defined by:

$$
\begin{aligned}
& w_{c-x}=u \frac{\partial q_{x}}{\partial x}+v \frac{\partial q_{x}}{\partial y}+w \frac{\partial q_{x}}{\partial z} ; \\
& w_{e-x}=q_{x} \frac{\partial u}{\partial x}+q_{y} \frac{\partial v}{\partial x}+q z \frac{\partial w}{\partial x} ; \\
& w_{c-y}=u \frac{\partial q_{y}}{\partial x}+v \frac{\partial q_{y}}{\partial y}+w \frac{\partial q_{y}}{\partial z} ; \\
& w_{e-y}=q_{x} \frac{\partial u}{\partial y}+q_{y} \frac{\partial v}{\partial y}+q_{z} \frac{\partial w}{\partial y} ; \\
& w_{c-z}=u \frac{\partial q_{z}}{\partial x}+v \frac{\partial q_{z}}{\partial y}+w \frac{\partial q_{z}}{\partial z} ; \\
& w_{e-z}=q_{x} \frac{\partial u}{\partial z}+q_{y} \frac{\partial v}{\partial z}+q_{z} \frac{\partial w}{\partial z} .
\end{aligned}
$$

$W_{c}, W_{e}$, and $\left(W_{c}+W_{e}\right)$ represent the contribution of the velocity, velocity gradient and combined velocity and velocity gradient to the transport of $q$, respectively. These three parameters also contain three directional quota components along $\mathrm{x}, \mathrm{y}$, and $\mathrm{z}$ directions, and are expressed as: $W_{c x}, W_{c y}, W_{c z}, W_{e x}, W_{e y}, W_{e z}$ and $\left(W_{c x}+W_{e x}\right),\left(W_{c y}+W_{e y}\right),\left(W_{c z}+W_{e z}\right)$, respectively. The higher the value of these parameters, the greater the contribution of transporting $q . W_{c x} / \Delta T, W_{e x} / \Delta T,\left(W_{c x}+W_{e x}\right) / \Delta T, q_{x} / \Delta T, W_{c y} / \Delta T, W_{e y} / \Delta T,\left(W_{c y}+\right.$ $\left.W_{e y}\right) / \Delta T, q_{y} / \Delta T, W_{c z} / \Delta T, W_{e z} / \Delta T,\left(W_{c z}+W_{e z}\right) / \Delta T, q_{z} / \Delta T$ are also normalized.

Thus, the local heat-transfer coefficient was obtained as follow:

$$
h_{\text {local }}=q_{w} /\left(T_{W}-T_{b}\right) .
$$

The HTP of $P R=1.5, R A=0^{\circ}, P R=0.5, R A=0^{\circ}$ and $P R=0.5, R A=10^{\circ}$ was explained. Since MLV played an important role in heat transfer, this section mainly discusses the four parameters in the y-direction. Those values were taken from two lines formed by the intersections of the plane $X O Z$ and planes $X=x 1$ and $X=x 2$ (see Figure 1d).

As shown in Figure 8a, the value of $W_{c y} / \Delta T$ was close to 0 in a large region, while the value of $W_{c y} / \Delta T$ changed slightly in $P R s$ and the amplitude of $W_{c y} / \Delta T$ increased slightly along with the $X$ position. This means that the DWPVGs slightly changed the velocity in the y-direction behind the DWPVGs. 


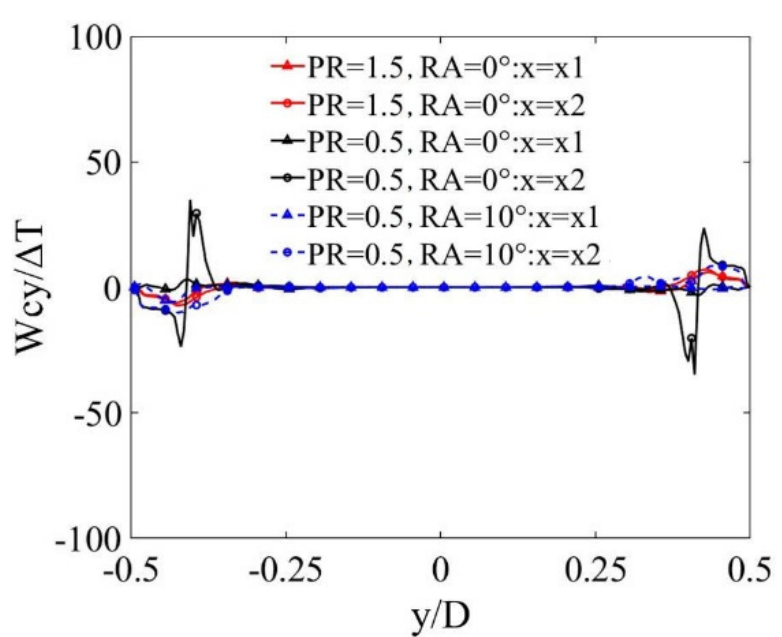

(a)

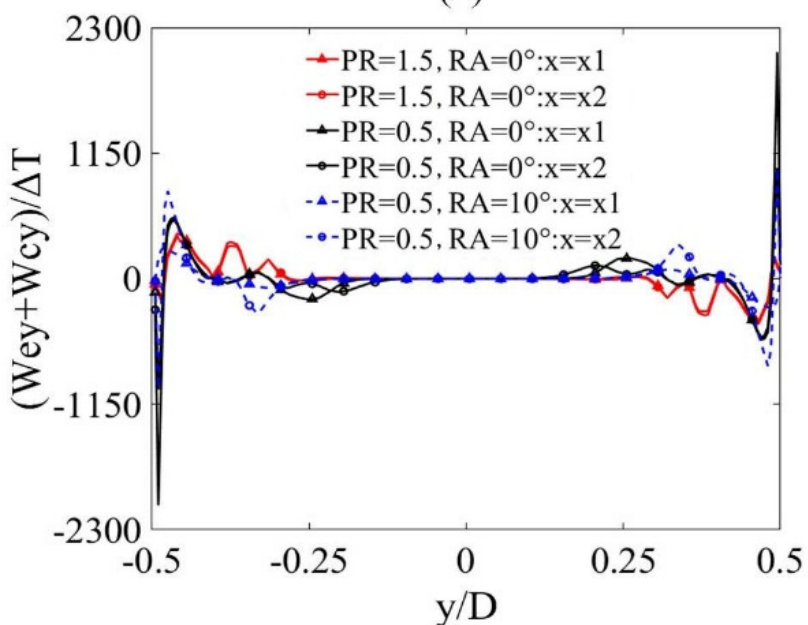

(c)

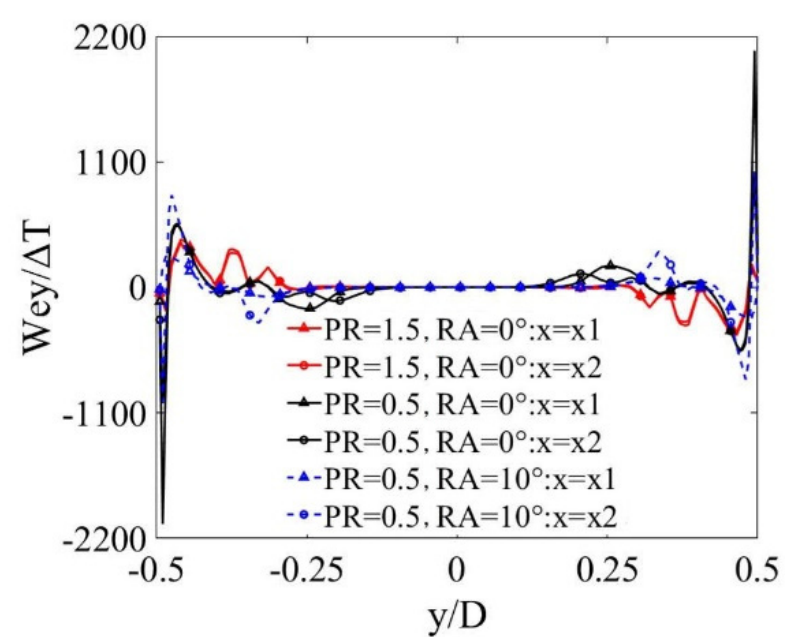

(b)

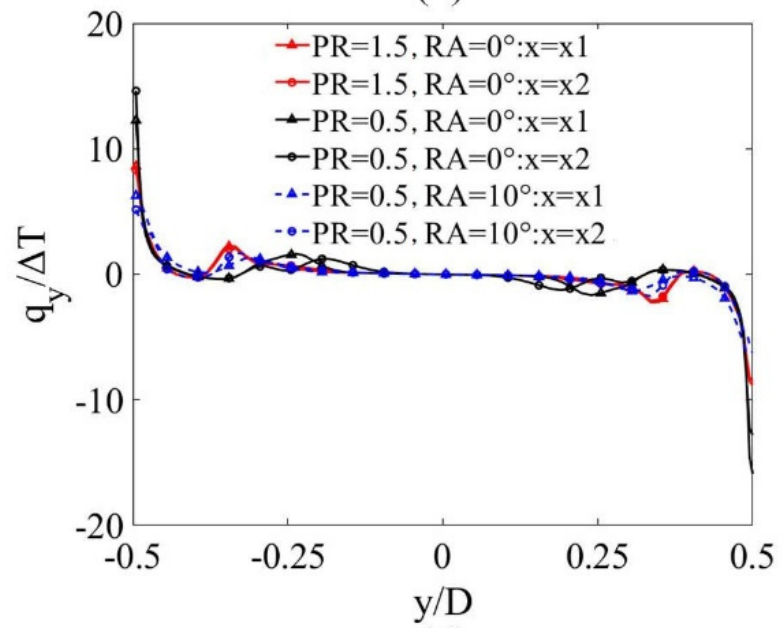

(d)

Figure 8. The distributions of (a) $W_{c y} / \Delta T$, (b) $W_{e y} / \Delta T$, (c) $\left(W_{c y}+W_{e y}\right) / \Delta T$, (d) $q_{y} / \Delta T$ on the lines inspected.

Figure $8 \mathbf{b}$ depicts the value of $W_{e y} / \Delta T$ in both cases and the value of $W_{e y} / \Delta T$ of $P R=0.5$ was much stronger than $P R=1.5$ near the wall and the amplitude of $W_{e y} / \Delta T$ became larger as it got closer to the wall along the $Y$ direction. There was a large turning point near the wall. The value of $W_{e y} / \Delta T$ in $\mathrm{X} 1$ position was almost twice that of $\mathrm{X} 2$ in $P R=0.5, R A=0^{\circ}$. In $P R=1.5$, the trend of $W_{e y} / \Delta T$ was similar in both $\mathrm{X} 1$ and $\mathrm{X} 2$ positions. The contribution of the velocity gradient has a great impact on the process of transporting $q_{y}$ near the wall.

The value of $\left(W_{c y}+W_{e y}\right) / \Delta T$ (Figure 8c) near the wall region was similar in both cases on the lines inspected, and the value of $\left(W_{c y}+W_{e y}\right) / \Delta T$ had a large amplitude change and was less dependent on the $\mathrm{X}$ position.

The variation of $q_{y} / \Delta T$ is shown in Figure $8 \mathrm{~d}$ which shows that the value of $q_{y} / \Delta T$ in $P R=0.5$ is much higher than $P R=1.5$. The value of $P R=0.5, R A=0^{\circ}$ was $40 \%$ lower than $P R=0.5, R A=30^{\circ}$ near the wall, while the amplitude of the value of $q_{y} / \Delta T \operatorname{did}$ not change when the $X$ position increased. This indicates that the longitudinal vortices played a positive role in the process of transporting $q_{y}$ only in certain areas. The figures highlight that MLV changed the intensity of $q_{y}$ 's transportation.

Figure 8 showed $W_{c y} / \Delta T, W_{e y} / \Delta T,\left(W_{c y}+W_{e y}\right) / \Delta T$ and $q_{y} / \Delta T$ in different cases. The MLV caused by the DWPVGs changed the contribution of the three parameters to transporting $q_{y}$ including velocity, the velocity gradient and the combined velocity and velocity gradient. MLV has different comprehensive contributions to velocity and velocity gradient and its comprehensive contribution to the transport of $q_{y}$ played a positive role 
locally. The most significant change took place in the local transport characteristics of $q_{y}$, meaning the existence of an MLV promoted the transport of $q_{y}$, leading to higher heat transfer performance. Thanks to the improvement of $q_{y}{ }^{\prime}$ s transportation, the HTP in $P R=0.5, R A=0^{\circ}$ was enhanced as well, while with increased $R A$, the transport of $q_{y}$ was deferred. This is to say that the HTP of larger $R A$ values was restrained.

In addition, the Nusselt number ratios $\left(N u / N u_{0}\right)$ were introduced to evaluate the augmentation of the tube's $N u$ values with the insertion of the DWPVGs, where $N u_{0}$ was obtained from the smooth tube. Figure 9 showss that the values of $N u / N u_{0}$ decreased slightly with increasing Re numbers.

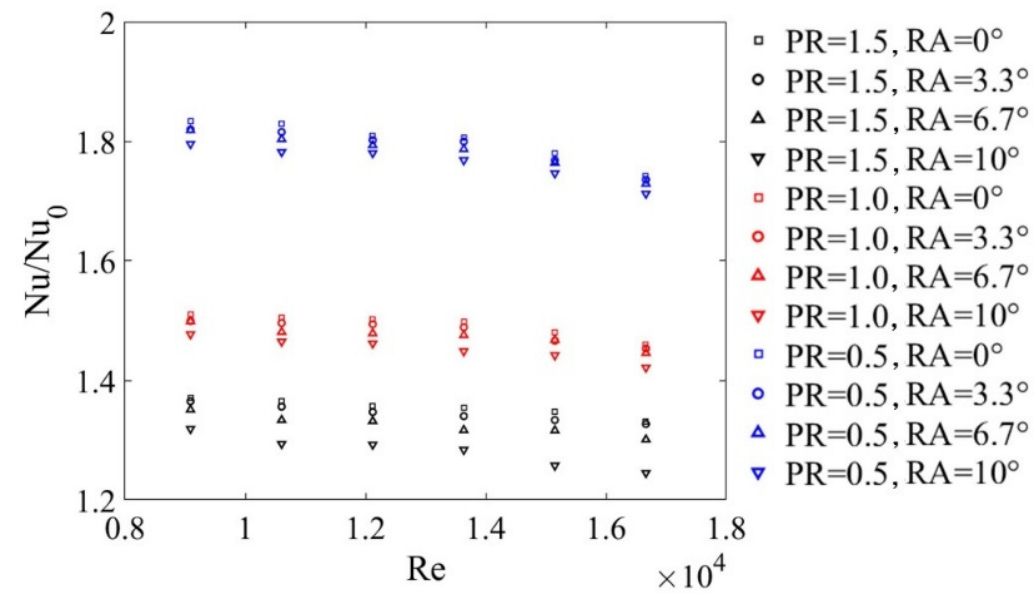

Figure 9. $\mathrm{Nu} / \mathrm{N} u_{0}$ versus $R e$ for different $P R s$ and $R A s$.

\subsection{Effect of $V G$ 's Arrangement Styles on Friction Factor}

Figure 10a shows the relationship between $R e$ and $f$ with different $P R$ s and $R A$ s. The $f$ values were obtained according to Equation (8). The experimental results highlight that the $f$ values were higher for the tubes with a DWPVG insertion because of the form drag from VGs. When the $R A$ and $R e$ were the same, the values of $f$ increased with decreasing $P R$ values. This is because more DWPVGs could fit into the tube if the $P R$ was smaller, resulting in more form drags and severe interaction among fluid, wall, and DWPVGs. When the $P R$ and $R e$ were the same, the $f$ values decreased as the $R A$ values went down. This is because the flow blockage went up with $R A$ values from $0^{\circ}$ to $10^{\circ}$ and resulted in lower speed vortices.
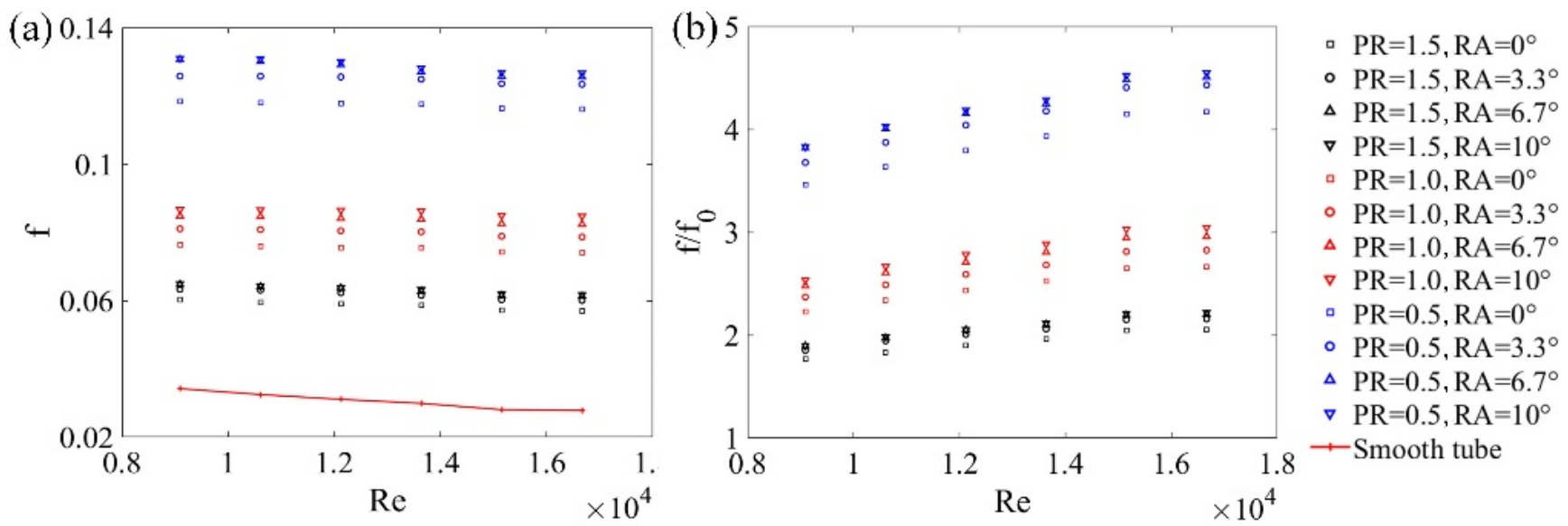

Figure 10. Effects of vortex generators on the $f$ for different $P R$ s and $R A$ s. (a) the relationship between $R e$ and $f$ with different $P R s$ and $R A s$; (b) the relationship between the friction efficient ratio $f / f_{0}$ and Re with different $P R s$ and $R A s$. 
Moreover, the friction efficient ratio $\left(f / f_{0}\right)$ was induced to qualify the pressure drop augmentation of the tube with DWPVGs to that of the tube absence of DWPVGs (see Figure 10b). The values of $f / f_{0}$ increased with increasing Re numbers.

\subsection{Effects of VG's Arrangement Styles on TEF}

Figure 11 portrayed the relationship of Re and TEF with different $P R$ s and RAs. An interesting finding was that the value of TEF decreased with the enlargement of $R e$. The TEF values increased with the decreasing $P R$ values due to higher $N u / N u_{0}$ augmentations. The TEF values decreased with increased $R A$ values $\left(0^{\circ} \leq R A \leq 10^{\circ}\right)$ because of higher $f / f_{0}$ values. The maximum value of TEF was 1.21 when $P R=0.5, R A=0^{\circ}$ at $R e=9090$.

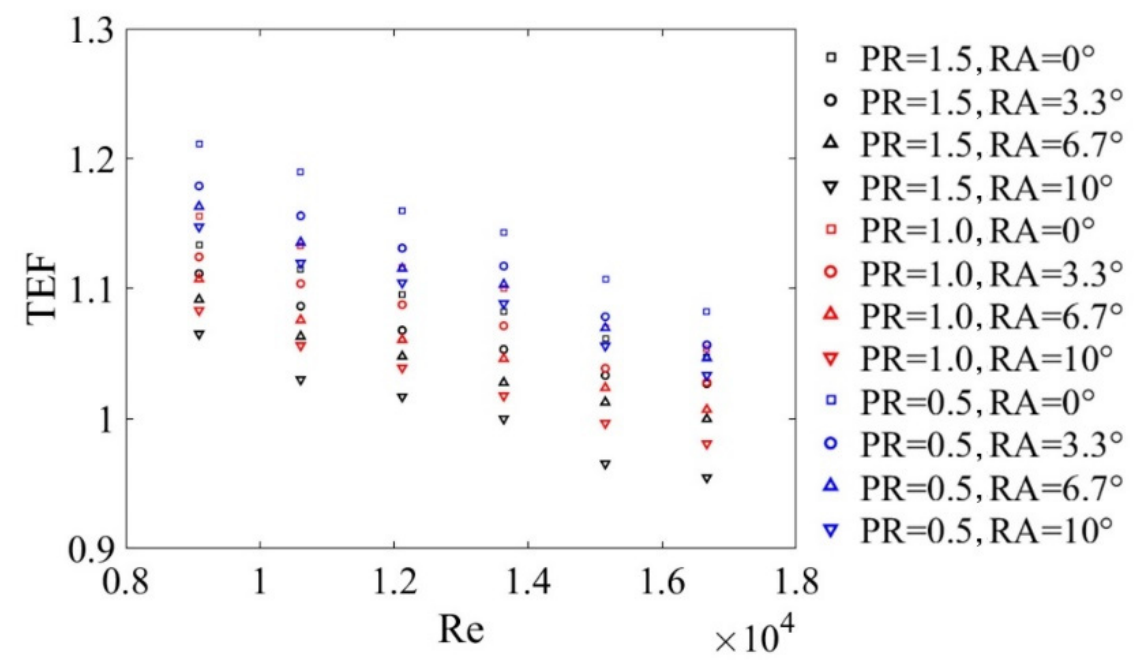

Figure 11. Effects of DWPVGs on the TEF for different $P R$ and $R A$.

\section{Comparison with Previous Work}

Figure 12 shows the TEF in the present work compared to other works. It can be that the TEF of the DWPVGs proposed was higher than the twisted rings [40], perforated conical rings [41], conical rings [42], cross hollow twisted tapes [29], and regularly spaced quadruple twisted tapes [29]. This would mean that the DWPVGs was an effective HTE technique in the state of turbulence. The TEF of the DWPVGs was lower than that of the punched delta-winglets [43], rectangular winglets [33] and horseshoe baffles [44]. Therefore, the structure of DWPVGs needs to be further improved in future studies.

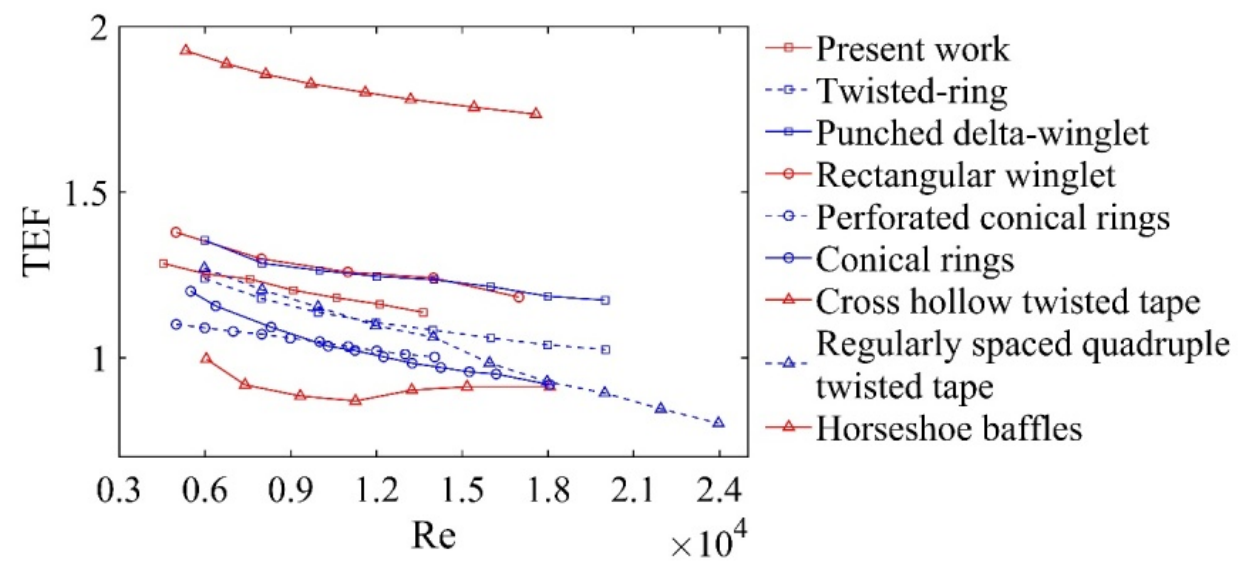

Figure 12. Comparisons of TEF between present work and previous works. 


\section{Conclusions}

In this paper, new DWPVGs were proposed and studied experimentally and numerically. The effects of three pitch ratios $(P R=0.5,1.0,1.5)$ and four rotation angles $\left(R A=0^{\circ}, 3.3^{\circ}, 6.7^{\circ}, 10^{\circ}\right)$ on thermal-hydraulic performance were studied. The main conclusions are as follows:

1. DWPVGs could enhance the HTP by enhancing the mixing strength of the hotter air near the wall and the colder air in the core flow region. The best HTP could be achieved by smaller $P R$ and lower $R A$ values.

2. Compared with the smooth tube, the $N u$ and $f$ increased by 1.24-1.83 times and 1.66-4.27 times, respectively. Considering the overall performance of the DWPVGs, the TEF was strongest when $P R=0.5, R A=0^{\circ}$ at $R e=9090$. That was TEF $=1.21$.

3. Longitudinal vortices could largely enhance the velocity gradient near the wall in the $y$-direction, which was the core reason for increasing the intensify of the transport of $q_{y}$.

Author Contributions: Conceptualization, software, validation, writing-original draft preparation, J.W.; writing - review and editing, project administration, T.F.; project administration, L.Z.; software, G.C.; software, F.-s.L. All authors have read and agreed to the published version of the manuscript.

Funding: This research was financially supported by the National Natural Science Foundation of China (Grant No. 51605345 and No. 51975425) and the Overseas Scholarship Program for Graduate Students by Wuhan University of Science and Technology.

Conflicts of Interest: The authors declared that there is no conflict of interest.

\section{References}

1. Alam, T.; Kim, M.-H. A comprehensive review on single phase heat transfer enhancement techniques in heat exchanger applications. Renew. Sustain. Energy Rev. 2018, 81, 813-839. [CrossRef]

2. Sheikholeslami, M.; Gorji-Bandpy, M.; Ganji, D.D. Review of heat transfer enhancement methods: Focus on passive methods using swirl flow devices. Renew. Sustain. Energy Rev. 2015, 49, 444-469. [CrossRef]

3. Jiao, Y.; Wang, J.; Liu, X. Heat transfer and flow characteristics in a rectangular channel with miniature cuboid vortex generators in various arrangement. Int. J. Therm. Sci. 2020, 153, 106335. [CrossRef]

4. Brandner, P.; Walker, G. Hydrodynamic performance of a vortex generator. Exp. Therm. Fluid Sci. 2003, 27, 573-582. [CrossRef]

5. Min, C.; Qi, C.; Kong, X.; Dong, J. Experimental study of rectangular channel with modified rectangular longitudinal vortex generators. Int. J. Heat Mass Transf. 2010, 53, 3023-3029. [CrossRef]

6. Zhang, L.; Yan, X.; Zhang, Y.; Feng, Y.; Li, Y.; Meng, H.; Zhang, J.; Wu, J. Heat transfer enhancement by streamlined winglet pair vortex generators for helical channel with rectangular cross section. Chem. Eng. Process. Process Intensif. 2020, 147, 107788. [CrossRef]

7. Akpinar, E.K.; Koçyiğit, F. Energy and exergy analysis of a new flat-plate solar air heater having different obstacles on absorber plates. Appl. Energy 2010, 87, 3438-3450. [CrossRef]

8. Kulkarni, K.; Afzal, A.; Kim, K.-Y. Multi-objective optimization of solar air heater with obstacles on absorber plate. Solar Energy 2015, 114, 364-377. [CrossRef]

9. Fiebig, M. Embedded vortices in internal flow: Heat transfer and pressure loss enhancement. Int. J. Heat Fluid Flow 1995, 16, 376-388. [CrossRef]

10. Ke, Z.; Chen, C.-L.; Li, K.; Wang, S.; Chen, C.-H. Vortex dynamics and heat transfer of longitudinal vortex generators in a rectangular channel. Int. J. Heat Mass Transf. 2019, 132, 871-885. [CrossRef]

11. Sun, Z.; Zhang, K.; Li, W.; Chen, Q.; Zheng, N. Investigations of the turbulent thermal-hydraulic performance in circular heat exchanger tubes with multiple rectangular winglet vortex generators. Appl. Therm. Eng. 2020, 168, 114838. [CrossRef]

12. Khoshvaght-Aliabadi, M.; Sartipzadeh, O.; Alizadeh, A. An experimental study on vortex-generator insert with different arrangements of delta-winglets. Energy 2015, 82, 629-639. [CrossRef]

13. Xu, Y.; Islam, M.D.; Kharoua, N. Numerical study of winglets vortex generator effects on thermal performance in a circular pipe. Int. J. Therm. Sci. 2017, 112, 304-317. [CrossRef]

14. Liang, G.; Islam, M.D.; Kharoua, N.; Simmons, R. Numerical study of heat transfer and flow behavior in a circular tube fitted with varying arrays of winglet vortex generators. Int. J. Therm. Sci. 2018, 134, 54-65. [CrossRef]

15. Xu, Y.; Islam, M.D.; Kharoua, N. Experimental study of thermal performance and flow behaviour with winglet vortex generators in a circular tube. Appl. Therm. Eng. 2018, 135, 257-268. [CrossRef]

16. Zhai, C.; Islam, M.D.; Simmons, R.; Barsoum, I. Heat transfer augmentation in a circular tube with delta winglet vortex generator pairs. Int. J. Therm. Sci. 2019, 140, 480-490. [CrossRef] 
17. Pourhedayat, S.; Pesteei, S.M.; Ghalinghie, H.E.; Hashemian, M.; Ashraf, M.A. Thermal-exergetic behavior of triangular vortex generators through the cylindrical tubes. Int. J. Heat Mass Transf. 2020, 151, 119406. [CrossRef]

18. Hatami, M.; Ganji, D.D.; Gorji-Bandpy, M. Experimental investigations of diesel exhaust exergy recovery using delta winglet vortex generator heat exchanger. Int. J. Therm. Sci. 2015, 93, 52-63. [CrossRef]

19. Oneissi, M.; Habchi, C.; Russeil, S.; Lemenand, T.; Bougeard, D. Heat transfer enhancement of inclined projected winglet pair vortex generators with protrusions. Int. J. Therm. Sci. 2018, 134, 541-551. [CrossRef]

20. He, Y.L.; Tao, W.Q.; Song, F.Q.; Zhang, W. Three-dimensional numerical study of heat transfer characteristics of plain plate fin-and-tube heat exchangers from view point of field synergy principle. Int. J. Heat Fluid Flow 2005, 26, 459-473. [CrossRef]

21. Baissi, M.T.; Brima, A.; Aoues, K.; Khanniche, R.; Moummi, N. Thermal behavior in a solar air heater channel roughened with delta-shaped vortex generators. Appl. Therm. Eng. 2020, 165, 113563. [CrossRef]

22. Lu, G.; Zhou, G. Numerical simulation on performances of plane and curved winglet type vortex generator pairs with punched holes. Int. J. Heat Mass Transf. 2016, 102, 679-690. [CrossRef]

23. Skullong, S.; Promvonge, P.; Thianpong, C.; Jayranaiwachira, N. Thermal behaviors in a round tube equipped with quadruple perforated-delta-winglet pairs. Appl. Therm. Eng. 2017, 115, 229-243. [CrossRef]

24. Song, K.; Tagawa, T.; Chen, Z.; Zhang, Q. Heat transfer characteristics of concave and convex curved vortex generators in the channel of plate heat exchanger under laminar flow. Int. J. Therm. Sci. 2019, 137, 215-228. [CrossRef]

25. Wijayanta, A.T.; Istanto, T.; Kariya, K.; Miyara, A. Heat transfer enhancement of internal flow by inserting punched delta winglet vortex generators with various attack angles. Exp. Therm. Fluid Sci. 2017, 87, 141-148. [CrossRef]

26. Gupta, A.; Roy, A.; Gupta, S.; Gupta, M. Numerical investigation towards implementation of punched winglet as vortex generator for performance improvement of a fin-and-tube heat exchanger. Int. J. Heat Mass Transf. 2020, 149, 119171. [CrossRef]

27. Zhou, G.; Ye, Q. Experimental investigations of thermal and flow characteristics of curved trapezoidal winglet type vortex generators. Appl. Therm. Eng. 2012, 37, 241-248. [CrossRef]

28. Eiamsa-Ard, S.; Samravysin, P. Characterization of Heat Transfer by Overlapped-Quadruple Counter Tapes. J. Heat Transf. 2018, 140. [CrossRef]

29. Samruaisin, P.; Changcharoen, W.; Thianpong, C.; Chuwattanakul, V.; Pimsarn, M.; Eiamsa-ard, S. Influence of regularly spaced quadruple twisted tape elements on thermal enhancement characteristics. Chem. Eng. Process. Process Intensif. 2018, 128, 114-123. [CrossRef]

30. Nakhchi, M.E. Experimental optimization of geometrical parameters on heat transfer and pressure drop inside sinusoidal wavy channels. Therm. Sci. Eng. Prog. 2019, 9, 121-131. [CrossRef]

31. Coleman, H.W.; Steele, W.G.; Buzhuga, M. Experimentation, Validation, and Uncertainty Analysis for Engineers. Noise Control Eng. J. 2010, 58, 343. [CrossRef]

32. Menter, F.R.; Kuntz, M.; Langtry, R. Ten Years of Industrial Experience with the SST Turbulence Model. Turbul. Heat Mass Transf. 2003, 4, 625-632.

33. Liu, H.-L.; Li, H.; He, Y.-L.; Chen, Z.-T. Heat transfer and flow characteristics in a circular tube fitted with rectangular winglet vortex generators. Int. J. Heat Mass Transf. 2018, 126, 989-1006. [CrossRef]

34. Gnielinski, V. New equations for heat and mass transfer in turbulent pipe and channel flow. Int. Chem. Eng. 1976, 16, 359-368. [CrossRef]

35. Taler, D. A new heat transfer correlation for transition and turbulent fluid flow in tubes. Int. J. Therm. Sci. 2016, 108, 108-122. [CrossRef]

36. Petukhov, B. Heat transfer and friction in turbulent pipe flow with variable physical properties. Adv. Heat Transf. 1970, 6, 503-564. [CrossRef]

37. Streeter, V.L.; Wylie, E.B. Fluid-Mechanics, 7th ed.; McGraw-Hill: New York, NY, USA, 1979.

38. Taler, D. Determining velocity and friction factor for turbulent flow in smooth tubes. Int. J. Therm. Sci. 2016, 105, 109-122. [CrossRef]

39. Zhang, Q.; Wang, L.-B.; Zhang, Y.-H. The mechanism of heat transfer enhancement using longitudinal vortex generators in a laminar channel flow with uniform wall temperature. Int. J. Therm. Sci. 2017, 117, 26-43. [CrossRef]

40. Thianpong, C.; Yongsiri, K.; Nanan, K.; Eiamsa-ard, S. Thermal performance evaluation of heat exchangers fitted with twisted-ring turbulators. Int. Commun. Heat Mass 2012, 39, 861-868. [CrossRef]

41. Nakhchi, M.E.; Esfahani, J.A. Numerical investigation of turbulent Cu-water nanofluid in heat exchanger tube equipped with perforated conical rings. Adv. Powder Technol. 2019, 30, 1338-1347. [CrossRef]

42. Ibrahim, M.M.; Essa, M.A.; Mostafa, N.H. A computational study of heat transfer analysis for a circular tube with conical ring turbulators. Int. J. Therm. Sci. 2019, 137, 138-160. [CrossRef]

43. Lei, Y.; Zheng, F.; Song, C.; Lyu, Y. Improving the thermal hydraulic performance of a circular tube by using punched delta-winglet vortex generators. Int. J. Heat Mass Transfer 2017, 111, 299-311. [CrossRef]

44. Promvonge, P.; Tamna, S.; Pimsarn, M.; Thianpong, C. Thermal characterization in a circular tube fitted with inclined horseshoe baffles. Appl. Therm. Eng. 2015, 75, 1147-1155. [CrossRef] 